Theories \& Applications, the International Edition

Printed Version : (ISSN 2090-5262)

Online Version : (ISSN 2090-5270)

November 2014, Volume 4, No. 3 Pages (65 - 76)

\title{
Identifying Standard Levels for Coordination of Motor Abilities in the 11-13 Year-Old Free Style Wrestlers.
}

\section{El-Sayd El-Mohamady Kandil}

Lecturer, Sports Training Department, Faculty of Physical Education, Mansoura University, Egypt.

\begin{abstract}
This study aims at Identifying standard levels for coordination of motor abilities in 11-13 year-old free style wrestlers. The descriptive method was used and the sample was convenience selected. It consisted of 186 junior free-style wrestlers in the age span 11 - 13 from six governorates in Egypt. Sample subjects, registered in the Egyptian Wrestling Federation in 2011 2012, were divided into two groups, one group, consisting of 30 juniors, and another a basic sample, consisting of 156 juniors. The main results included The Specific coordination of motor abilities of the junior free wrestler are the ability of motor Coupling - the ability to assess position - the ability to make the suitable effort - the ability to adapt to changing positions - the ability of Reaction- the ability of motor balance The standard levels of coordination of motor abilities were identified (the ability of motor Coupling - the ability to assess position - the ability to make the suitable effort - the ability to adapt to changing positions - the ability of Reaction - the ability of motor balance) for 11-13 year-old junior free wrestlers Values of raw scores and the corresponding standard levels in testing each coordination of motor ability show the variety in juniors' levels compared to peers. This helps us reach some positive results which we can use in evaluating performance objectively and guide the training of juniors in this age span, Recommendations included using the tests of coordination of motor abilities studied in evaluating the performance level of free style wrestling juniors; conducting research aiming at identifying the special coordination of motor abilities and focusing on the development of such abilities in Greco-Roman wrestling and other individual and team sports; conducting research aiming at extracting standard levels for coordination of motor abilities in juniors of various age groups in both types of wrestling and in other individual and team sports; developing training programs to upgrade the standard of coordination of motor abilities and skillful and tactical performance of free style and Greco-Roman wrestling in young age stages.
\end{abstract}

Key word: Standard Levels - Coordination of motor Abilities - Free Style Wrestlers

\section{Introduction}

S tandardized tests are becoming more and more important in the sporting field where they are beneficial to sports trainers. The level of players cannot be identified without tests, which are used as a research method. This is why the design and standardization of tests are important. (2)

Standards are one of the basic aims of test standardization. It is through this process of standardization, applied to the research community, that standards are derived. The importance of standards to studies conducted in the field of physical education and sport is obvious when using test sets as "batteries". This is due to the fact that different measuring units are used in tests included in such batteries. Some tests use the centimeter as a measuring unit, some use time, others still use frequency. This is why a raw score is transformed to a standard score, thus making evaluation easier. Standard scores are usually tabulated as "scales". (12)

standards (standard scores) should not, however, be regarded as standards of performance, goals to be attained by individuals or what an individual must achieve. Rather, they should be considered as a means of comparison and evaluation to be utilized when predicting possibilities of success, identifying points of strength and weakness in an individual and measuring the development and enhancement achieved in his/her level of performance. (10)

\section{Requirements of developing standards}

1. Identifying tests required and conditions of the application thereof, together with instructions of proceeding, calculating scores, etc;

2. Standardization sample must be representative of the original community (showing normalcy, randomly selected, large in number and representing the commun;

3. Applying tests and using standard scores;

4. Considering the timing because standard scores (standards) are temporary and changeable with the elapse of time;

5. Good presentation through clear tables that can be easily used for purposes of diagnosis or comparison. (11)

Standards are often used in evaluating performance of psycho-motor skills, various sport activities, and also in assessing individuals' levels of achieving activities that require mastering and perfection. Teaching, training and practice are therefore important as is the need to ensure individuals have reached an acceptable degree of 
performance, so that the levels reached could be used as referential benchmarks to evaluate performance. (10)

Motor performance is generally regarded as processes of a complex structure. It might be combined, successive or feint, depending on the playing situations occurring during matches, with a high degree of motor coordination. In their entirety, performance require high levels of coordination of motor abilities in all players whatever the differences are between their levels, in view of the reciprocal relationships between coordination of motor abilities and motor tactics. (13)

Developing the level of coordination of motor abilities plays an important role in acquiring motor skills because the appropriate level of such abilities is essential to learn the skills. The extent to which motor skills are mastered, which reflects the combined foundation of an individual's level, helps develop coordination of motor abilities because training seeking to change the external conditions of skills leads to identifying the quantity and quality of a player's coordination of motor abilities. Consequently, coordination of motor abilities and motor skills combine to form the coordination foundations and develop the level while practicing sport. (6)

Motor coordination is the ability to perform motor tasks smoothly and accurately using the feeling and the sequence of consecutive muscle contractions which are affected by the range of motion of joints. Motor coordination is important when the junior or player perform movements that require the simultaneous use of more than one part of the body or different muscle groups in different directions. It helps a player use his or her body easily, quickly and smoothly to achieve the results desired. (18)

The term "coordination of motor abilities" indicates phases of movements or parts of movements combined together in the framework of motor performance. (1)

Coordination of motor abilities is "an individual's ability to carry out complex (combined) movements rapidly and accurately under different circumstances and conditions". Neumaier added that this definition is limited to complex and combined movements, because simple and easy movements that are performed rapidly and accurately under different circumstances and conditions may also belong to coordination of motor abilities. (17)

Coordination of motor abilities emanate from the requirements of sports performance and are dictated by an individual's ability to perform motor skills accurately perfectly.

Coordination of motor abilities do not appear individually, but are associated to other conditions of sport achievement, such as physical abilities and skillful and tactical performance. They are also inter-connected in most cases. They help build up whole movement from partial movements in a coordinated manner. When coordination of motor abilities are coordinated, the highest level of the general motor coordination required for performing motor tasks. (8)

A good level of coordination of motor abilities help players to quickly learn and acquire motor skills, so that time is used for training and enhancing performance. A high level of coordination help players diversify skillful performance and improve the technical level as coordination of motor abilities are directly proportional to skillful performance, affect and is affected by it. (9) (14)

Coordination of motor abilities are important because they have an effect on speed, accuracy and skill acquisition time. They are directly based on the level of functional and morphological efficiency. Training the coordination of motor abilities can be done either individually or through training units for the skillful and physical aspects. coordination of motor abilities can be divided into two types, based on terminology. One type is the ability of regulation which has a neuro-psychological basis, while the other includes the psycho motor abilities connecting cognitive aspects. Both types are to be found in the field of sport. (22)

Coordination of motor abilities are a cornerstone of sports achievement necessary for the enhancement of the technical performance of juniors and players alike, because coordination of motor abilities results from the qualitative analysis of the specialized activity requirements. Seeking to develop them therefore positively affects the skillful aspect, because they are the foundations for achievement related to motor control processes during the different motor performances. Possessing such abilities by juniors and players enables them to achieve the best scores of motor performance coordination required for achieve motor tasks. (7)

Objective observations by the author of this paper, as coach and lecturer to third and fourth year students of the faculty, together with a follow-up of the national wrestling championships for juniors and players, showed inter- and intra- age group variations in coordinative aspects, reflected in differences in skillful performance. This triggered a review of literature on the subject to find out whether there are tests to measure the level of coordination of motor abilities. The current locally applied tests were found to be insufficient, and they do not set up standard levels for coordination of motor abilities in junior Greco-Roman wrestlers, to be used in measuring the coordination of motor abilities in juniors so that a trainer would be aware of the junior's level of such abilities, and be able to rate them, compared to their peers in the same age group, and track the development of levels of the abilities. In this paper, some tests have been designed and standardized to measure coordination of motor abilities and setting standard levels thereof. Results, hopefully positive, may be used in the selection and raining of junior wrestlers, and also in the scientific evaluation of performance. 


\section{Objective of the research}

- The research aims at identifying standard levels for coordination of motor abilities in the 11-13 year-old free style wrestlers through setting up standard levels for the coordination ability tests for the 11-13 year-old free style wrestling juniors.

\section{Research question}

- What are the standard levels for the coordination of motor abilities tests for the 11-13 year-old free style wrestling juniors?

\section{Research procedures}

\section{Methodology}

The descriptive method was used, being suitable for this type of study.

\section{Research Community and Sample:}

The research community included 11-13 year-old free style wrestling juniors in the governorates of Daqahliya, Sharqiya, Damietta, Cairo, Giza and Kafr el-Sheikh. The sample was convenience selected and consisted of 156 juniors in addition to 30 juniors representing the pilot sample. Table 1 shows the distribution of players.

Table (1)

Distribution of research sample

\begin{tabular}{|c|c|c|}
\hline No & Governorate & Number \\
\hline 1 & Daqahliya governorate & 45 \\
\hline 2 & Sharqiya governorate & 24 \\
\hline 3 & Damietta governorate & 23 \\
\hline 4 & Kafr el-Sheikh governorate & 25 \\
\hline 5 & Cairo governorate & 37 \\
\hline 6 & Giza governorate & 27 \\
\hline
\end{tabular}

\section{Homogeneity of Sample}

Table (2)

Mean, standard deviation and contortion coefficient of the basic sample in the basic variables $(N=186)$

\begin{tabular}{|c|c|c|c|c|c|c|}
\hline No & Variables & Measuring unit & Mean & Median & Standard deviation & $\begin{array}{c}\text { Contortion } \\
\text { coefficient }\end{array}$ \\
\hline 1 & Age & Year & 11.97 & 12 & 0.16 & $0.562-$ \\
\hline 2 & Height & Cm & 153.64 & 150 & 7.314 & 1.493 \\
\hline 3 & Weight & Kgm & 45.19 & 40 & 8.04 & 1.937 \\
\hline 4 & Training age & Month & 11.53 & 12 & 2.01 & $0.701-$ \\
\hline
\end{tabular}

Table (2) shows the values of mean, standard deviation and coefficient of contortion for the basic measurements of the basic study sample in the variables of age, height, weight and training age. It shows normalcy of distribution of the basic study sample as the contortion coefficient values ranged between -0.701 and 1.937 , which means that they are below the +3 level.

\section{Data Collecting Means:}

A review was made of reference works and literature both in Arabic and English which are related to the subject of the research as well as the internet. The author of this paper benefited from and was guided by results of such studies and references to identify the correct concepts of coordination of motor abilities and their relation to motor performance in individual games, specially free style wrestling, and also to identify the profile of coordination requirements of motor tasks in general and of wrestling in particular.

\section{Coordination of motor Abilities of Wrestlers}

Coordination of motor abilities were submitted to experts (attachment 1). The polls' results showed the coordination of motor ability of free wrestling juniors as shown in table (3). 
Table (3)

Percentages of experts' opinions about the main coordination of motor abilities appropriate for the 11-13 year-old group age in free style wrestling

$\mathbf{N}=6$

\begin{tabular}{|c|c|c|c|c|c|}
\hline \multirow{2}{*}{ No } & \multirow{2}{*}{ Name of ability } & \multicolumn{3}{|c|}{ Agreement } \\
\cline { 3 - 6 } & & & \multicolumn{2}{c|}{ Agree } & \multicolumn{2}{c|}{ Don't agree } \\
\cline { 3 - 6 } & & No. & $\%$ & No. & - \\
\hline 1 & Ability to adapt to changing positions & 6 & $\% 100$ & - & - \\
\hline 2 & Ability to make the suitable effort & 6 & $\% 100$ & - & $\% 16$ \\
\hline 3 & Ability to assess the position & 5 & $\% 84$ & 1 & - \\
\hline 4 & Ability of Of Motor Reaction & 6 & $\% 100$ & - & - \\
\hline 5 & Ability of motor Coupling & 6 & $\% 100$ & - & $\% 33.33$ \\
\hline 6 & Ability of motor flexibility & 4 & $\% 66.66$ & 2 & $\% 16$ \\
\hline 7 & Ability of motor balance & 5 & $\% 84$ & 1 & \\
\hline
\end{tabular}

Author accepted $80 \%$ and more as a percentage of accepting coordination of motor abilities related to the combined skillful performance:

- $\quad$ The Ability of Motor Coupling

- Ability to assess the position

- $\quad$ Ability to make the suitable effort

- Ability to adapt to changing positions

- The Ability Of Motor Reaction

- $\quad$ Ability of motor balance

\section{Standards of Choosing Experts:}

- Academic experience, because all experts are faculty staff members in faculties of physical education.

- $\quad$ Field experience in wrestling.

The wrestlers' coordination of motor abilities test battery used by El-Sayd El-Mohamady Kandil 2012 (5) was used in this paper, including:

1. Speed of combined motor response (falling on the right foot);

2. The muscular-motor feeling of the strength of arms, shoulders and trunk;

3. The time of joining the motor chain;

4. Situational wrestling from $2 \mathrm{~m}$ back step;

5. The bridge movement while balancing on one foot and the forehead;

6. Adapting to changing positions (number of falls on the foot).

The second test (the muscular-motor feeling of the strength of arms, shoulders and trunk) was modified so that the medical ball weighed $3 \mathrm{kgm}$ instead of $5 \mathrm{kgm}$ to be suitable to the age group. The third test (the time of joining the motor chain) was modified so that near cradle skill was cancelled and the two other skills were retained. The fifth test (the bridge movement while balancing on one foot and the forehead) was modified to (back jump on one foot for $4.5 \mathrm{~m}$ ) in view of the similarity of performance to that of free style wrestling. The sixth test (adapting to changing positions (number of falling on the foot)) was modified to (performing different skills from different positions in the shortest time) attachment 2 .

\section{Research Measurements and Tests:}

- Anthropometric measurements (age - height - weight training age)

\section{- Coordination of motor ability measurement tests}

1. Speed of combined motor reaction (falling on the right foot);

2. The muscular-motor feeling of the strength of arms, shoulders and trunk (throwing a $3 \mathrm{kgm}$ medical ball backwards);

3. The time of joining the motor chain;

4. Situational wrestling from $2 \mathrm{~m}$ back step;

5. back jump on one foot for $4.5 \mathrm{~m}$;

6. Adapting to changing positions (performing different skills from different positions in the shortest time).

\section{Research Equipment's and Tools:}

- Restameter to measure height

- Calibrated medical balance to measure weight

- $\quad$ Measurement tape in meters

- $\quad$ Medical ball (3kgm)

- $1 / 100$ s digital stop-watch

- Digital video camera

Pilot Studies: 
Two pilot studies were conducted aiming at making sure of the suitability of coordination of motor abilities tests chosen for the 11-13 year-old age span, putting the tests in their final form, making sure of the suitability of the tools used in taking measurements and finding their scientific qualities before applying them to the basic research sample. Studies were conducted on a sample of 30 wrestling juniors from Daqahliya governorate.

\section{First Pilot Study:}

The first pilot study was conducted in the period 12/3/2012 to $18 / 3 / 2012$ on a sample of 10 players from Mansoura Sports Stadium to make sure of the suitability of tests designed by the author to measure coordination of motor abilities and to the age group studied. The study resulted in identifying the suitable distances and making sure of the safety and accuracy of measurement tools used in measurements in each test.

\section{Second Pilot Study:}

After modifying the tests and putting them in their final form, a pilot study was conducted aiming at finding the scientific qualities of these tests (validity - reliability) reached by the author to measure coordination of motor abilities of free style wrestling juniors in the age group 1113 year-old on a sample of 20 free style wrestlers in Dekernes Club, from the original community of research and outside the research sample. Discrimination validity was used to calculate the validity of the tests and the test \& retest method on a sample of 10 players in the same community to calculate reliability.

Table (4)

Discriminant validity of coordination of motor abilities tests for junior free style wrestlers $(\mathrm{N} 1=\mathrm{N} 2=10)$

\begin{tabular}{|c|c|c|c|c|c|c|c|c|}
\hline \multirow[t]{2}{*}{ No } & \multirow[t]{2}{*}{ Variables } & \multirow{2}{*}{$\begin{array}{c}\text { Measurement } \\
\text { unit }\end{array}$} & \multirow[t]{2}{*}{ Name of Test } & \multicolumn{2}{|c|}{$\begin{array}{l}\text { Discriminating } \\
\text { group }\end{array}$} & \multicolumn{2}{|c|}{$\begin{array}{c}\text { Non- } \\
\text { discriminating } \\
\text { group }\end{array}$} & \multirow[t]{2}{*}{ T-value } \\
\hline & & & & mean & $\begin{array}{l}\text { Standard } \\
\text { deviation }\end{array}$ & mean & $\begin{array}{r}\text { Standard } \\
\text { deviation } \\
\end{array}$ & \\
\hline 1 & Ability of Reaction & $\mathrm{s}$ & falling on the foot & 0.808 & 0.071 & 1.482 & 0.129 & *28.185 \\
\hline 2 & $\begin{array}{l}\text { Ability to make the } \\
\text { suitable effort }\end{array}$ & $\mathrm{cm}$ & $\begin{array}{c}\text { throwing a } 3 \mathrm{kgm} \text { medical ball } 2 \mathrm{~m} \text { backwards } \\
\text { using both hands }\end{array}$ & 13.789 & 1.436 & 70.811 & 4.789 & $* 70.236$ \\
\hline 3 & $\begin{array}{l}\text { Ability to assess the } \\
\text { position }\end{array}$ & $\mathrm{cm}$ & situational wrestling from $2 \mathrm{~m}$ backwards & 10.395 & 1.264 & 34.432 & 2.102 & $* 60.204$ \\
\hline 4 & Ability of motor Coupling & $\mathrm{s}$ & time of relating the motor chain & 1.125 & 0.175 & 2.203 & 0.108 & *31.949 \\
\hline 5 & $\begin{array}{l}\text { Ability to adapt to } \\
\text { changing positions }\end{array}$ & $\mathrm{s}$ & $\begin{array}{l}\text { performing different skills from different } \\
\text { positions in the shortest time }\end{array}$ & 9.947 & 0.837 & 14.865 & 1.566 & $* 17.022$ \\
\hline 6 & Ability of motor balance & s & Jumping back on one foot for $4.5 \mathrm{~m}$ & 5.830 & 0.393 & 10.099 & 0.707 & $* 32.453$ \\
\hline
\end{tabular}

Tabular $T$ value at freedom degree of 18 and significance level of $0.05=1.673$

* = significant

Table 4 shows that there are statistically significant differences between the mean scores of the two discriminate and non-discriminate groups in the coordination of motor abilities tests, favoring the discriminate group, as the calculated $\mathrm{T}$ value is higher than its tabular value at the significance level of 0.05 . this demonstrates validity of the tests used and their ability to discriminate between different levls.

Table (5)

Reliability of coordination of motor abilities tests for junior free style wrestlers ( N $1=N 2=10)$

\begin{tabular}{|c|c|c|c|c|c|c|c|c|}
\hline \multirow[t]{2}{*}{$\mathrm{No}$} & \multirow[t]{2}{*}{ Variables } & \multirow{2}{*}{$\begin{array}{c}\text { Measurement } \\
\text { unit }\end{array}$} & \multirow[t]{2}{*}{ Name of Test } & \multicolumn{2}{|c|}{$\begin{array}{l}\text { Discriminating } \\
\text { group }\end{array}$} & \multicolumn{2}{|c|}{$\begin{array}{l}\text { Non- } \\
\text { discriminating } \\
\text { group }\end{array}$} & \multirow[t]{2}{*}{ T-value } \\
\hline & & & & mean & $\begin{array}{l}\text { Standard } \\
\text { deviation }\end{array}$ & mean & $\begin{array}{r}\text { Standard } \\
\text { deviation }\end{array}$ & \\
\hline 1 & Ability of Reaction & $\mathrm{S}$ & falling on the foot & 0.714 & 0.022 & 0.719 & 0.026 & $* 0.916$ \\
\hline 2 & $\begin{array}{l}\text { Ability to make the } \\
\text { suitable effort }\end{array}$ & $\mathrm{Cm}$ & $\begin{array}{l}\text { throwing a } 3 \mathrm{kgm} \text { medical ball } 2 \mathrm{~m} \\
\text { backwards using both hands }\end{array}$ & 11.8 & 0.789 & 12.2 & 1.229 & *0.735 \\
\hline 3 & $\begin{array}{l}\text { Ability to assess the } \\
\text { position }\end{array}$ & $\mathrm{Cm}$ & situational wrestling from $2 \mathrm{~m}$ backwards & 8.7 & 0.483 & 8.9 & 0.568 & *0.757 \\
\hline 4 & $\begin{array}{l}\text { Ability of motor } \\
\text { Coupling }\end{array}$ & $\mathrm{S}$ & time of relating the motor chain & 0.908 & 0.183 & 0.888 & 0.191 & *0.888 \\
\hline 5 & $\begin{array}{l}\text { Ability to adapt to } \\
\text { changing positions }\end{array}$ & S & $\begin{array}{l}\text { performing different skills from different } \\
\text { positions in the shortest time }\end{array}$ & 8.9 & 0.316 & 9.2 & 0.422 & *0.759 \\
\hline 6 & Ability of motor balance & S & Jumping back on one foot for $4.5 \mathrm{~m}$ & 5.442 & 0.062 & 5.42 & 0.087 & $* 0.863$ \\
\hline
\end{tabular}

Tabular $T$ value at freedom degree of 8 and significance level of $0.05=.632$ 
Table (5) shows that there is a significant direct relationship between the first and second application of the coordination ability tests, as the values of calculated coefficient of correlation is higher than its tabular value at a significant level of 0.05 , thus demonstrating reliability of tests.

\section{The Basic Study:}

The basic study was conducted in the period from Saturday $7 / 4 / 2012$ to Monday $18 / 6 / 2012$ on a sample of under 11-13 year-old junior free style wrestlers as follows:

- Daqahliya 7/4 - 18/4/2012.

- $\quad$ Damietta 20/4 - 25/4/2012.

- $\quad$ Kafr el-Sheikh 28/4 - 10/5/2012.

- Sharqiya $15 / 5-22 / 5 / 2012$.

- $\quad$ Cairo 25/5 - 7/6/2012.

- $\quad$ Giza $9 / 6$ - 18/6/2012

Statistical Treatments:

- Mean
- Median

- $\quad$ Range

- Standard deviation

- Coefficient of contortion

- Independent samples T test

- Pearson coefficient of correlation

\section{Result Presentation and Discussion:}

In the light of research procedures and results of applying the coordination of motor ability tests (ability of Reactionability to make the suitable effort - ability of direction ability of motor Coupling - ability to adapt to changing positions - ability of motor balance) in the 11-13 year-old junior free style wrestlers, results of the research question are presented and discussed in the following part:

- Results of the research question: what are the standard levels of coordination of motor ability tests for the 11-13 year-old junior free style wrestlers.

Table (6)

Mean, standard deviation, range and standard levels of the ability of Reaction

\begin{tabular}{|c|c|c|c|c|c|}
\hline \multirow{2}{*}{ Level } & Mean & Deviation & Range & Lowest score & $\begin{array}{c}\text { Highest } \\
\text { score }\end{array}$ \\
\cline { 2 - 6 } & 1.13 & 0.26 & 1.10 & 0.67 & 1.77 \\
\cline { 2 - 6 } & Standard score & T score & Time in seconds & Number & $\%$ \\
\hline Excellent & -1.77 to less than -0.92 & 32.3 to less than 40.8 & 0.67 to less than 0.89 & 35 & $\% 22.44$ \\
\hline Very good & -0.92 to less than -0.08 & 40.8 to less than 49.2 & 0.89 to less than 1.11 & 45 & $\% 28.85$ \\
\hline Good & -0.08 to less than 0.77 & 49.2 to less than 57.7 & 1.11 to less than 1.33 & 44 & $\% 28.21$ \\
\hline Fair & 0.77 to less than 1.62 & 57.7 to less than 66.2 & 1.33 to less than 1.55 & 22 & $\% 14.10$ \\
\hline Low & 1.62 to less than 2.64 & 66.2 to less than 74.6 & 1.55 to less than 1.77 & 10 & $\% 6.41$ \\
\hline \multicolumn{7}{|c|}{ Total } & 156 & 100 \\
\hline
\end{tabular}

Table (6) shows the standard levels and the corresponding raw scores of the ability of Reaction in 11-13 year-old junior free style wrestlers. Raw scores corresponding to the excellent level ranged from $0.67 \mathrm{~s}$ to less than $0.89 \mathrm{~s}$. Number of juniors reaching the excellent level was 35 with a percentage of $22.44 \%$ of the total number of the sample. The very good level ranged from $0.89 \mathrm{~s}$ to less than $1.11 \mathrm{~s}$. Number of juniors reaching the very good level was 45 with a percentage of $28.85 \%$ of the total number of the sample. The good level ranged from $1.11 \mathrm{~s}$ to less than $1.33 \mathrm{~s}$. Number of juniors reaching the good level was 44 with a percentage of $28.21 \%$ of the total number of the sample. The fair level ranged from $1.33 \mathrm{~s}$ to less than $1.55 \mathrm{~s}$. Number of juniors reaching the fair level was 22 with a percentage of $14.10 \%$ of the total number of the sample. The low level ranged from $1.55 \mathrm{~s}$ to less than $1.77 \mathrm{~s}$. Number of juniors reaching the low level was 10 with a percentage of $6.41 \%$ of the total number of the sample. This means that based on percentage of the sample in each level, the order of levels was as follows: very good - good - excellent - fair - low. This may be due to the similarity between the test and the technical performance of free style wrestling, which had an effect on the high level reached by the sample in the results of this test. It may also be due to the high skillful level of the juniors in this age span and the mutual effect between such a level and the coordination ability level, besides the characteristics of biological maturity of this age. Ossama Kamel Rateb \& Amin Anwar El-Kholy (1994) and Ossama Kamel Rateb (1999) (3), (4) suggest that the age span 11-13 years is a stage of stability in the development in the nervous system and the person is very close to a ultimate maturity. This stability may favor juniors at this age in excelling in situation that required rapid reactions when achieving the motor activity of the skills, as is the case with the Reaction ability test studied in this paper. 
Form (1)

levels of the ability of Reaction

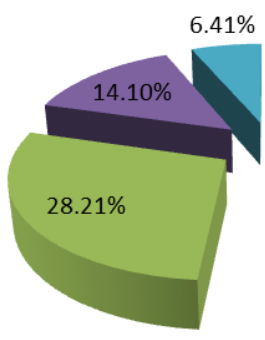

$\%$

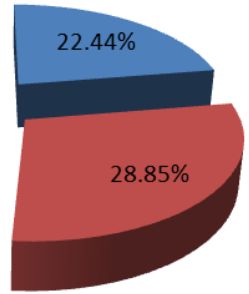

Excellent

very good

Good

Fair

- Low

Table (7)

Mean, standard deviation, range and standard levels of the ability to make the suitable effort

\begin{tabular}{|c|c|c|c|c|c|}
\hline \multirow{2}{*}{ Level } & Mean & Deviation & Range & Lowest score & $\begin{array}{c}\text { Highest } \\
\text { score }\end{array}$ \\
\cline { 2 - 6 } & 40.34 & 23.75 & 69.00 & 11.00 & 80.00 \\
\cline { 2 - 7 } & Standard score & T score & Distance $(\mathrm{cm})$ & Number & $\%$ \\
\hline Excellent & -1.23 to less than -0.65 & 37.6 to less than 43.5 & 11 to less than 24.8 & 66 & $\% 42.31$ \\
\hline Very good & -0.65 to less than -0.07 & 43.5 to less than 49.3 & 24.8 to less than 38.6 & 13 & $\% 8.33$ \\
\hline Good & -0.07 to less than 0.51 & 49.3 to less than 55.1 & 38.6 to less than 52.4 & 10 & $\% 0.41$ \\
\hline Fair & 0.51 to less than 1.09 & 55.1 to less than 60.9 & 52.4 to less than 66.2 & 37 & $\% 23.72$ \\
\hline Low & 1.09 to less than 1.67 & 60.9 to less than 66.7 & 66.2 to less than 80 & 30 & $\% 19.23$ \\
\hline & \multicolumn{3}{|l}{ Total } & 156 & 100 \\
\hline
\end{tabular}

Table (7) shows the standard levels and the corresponding raw scores of the ability to make the suitable effort in 11-13 year-old junior free style wrestlers. Raw scores corresponding to the excellent level ranged from $11 \mathrm{~cm}$ to less than $24.8 \mathrm{~cm}$. Number of juniors reaching the excellent level was 66 with a percentage of $42.31 \%$ of the total number of the sample. The very good level ranged from $24.8 \mathrm{~cm}$ to less than $38.6 \mathrm{~cm}$. Number of juniors reaching the very good level was 13 with a percentage of $8.33 \%$ of the total number of the sample. The good level ranged from $38.6 \mathrm{~cm}$ to less than $52.4 \mathrm{~cm}$. Number of juniors reaching the good level was 10 with a percentage of $6.41 \%$ of the total number of the sample. The fair level ranged from $52.4 \mathrm{~cm}$ to less than $66.2 \mathrm{~cm}$. Number of juniors reaching the fair level was 37 with a percentage of $23.72 \%$ of the total number of the sample. The low level ranged from $66.2 \mathrm{~cm}$ to less than $80 \mathrm{~cm}$. Number of juniors reaching the low level was 30 with a percentage of $19.23 \%$ of the total number of the sample. This means that based on percentage of the sample in each level, the order of levels was as follows: excellent - fair low - very good - good. This may be due to the high technical level of free style wrestlers (research sample). This increased coordination of the strength used to achieve the desired results when performing the test. This conforms with the definition of ability by Juhans Rea Engborg Rieter (1988) (16) as the ability to make the suitable effort.

Form (2)

levels of the ability of make the suitable effort
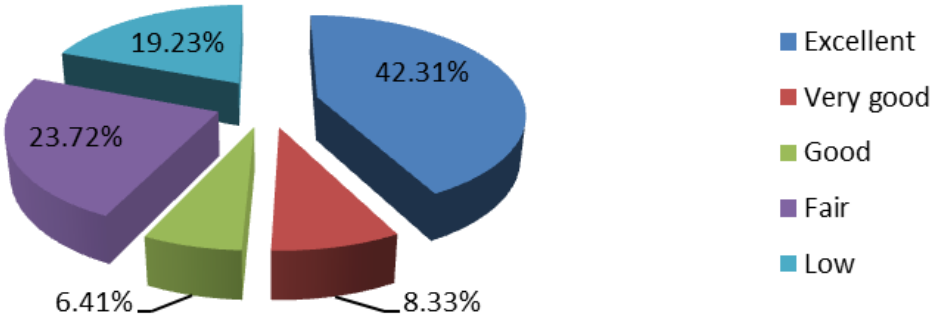
Table (8)

Mean, standard deviation, range and standard levels of the ability to assess the position

\begin{tabular}{|c|c|c|c|c|c|}
\hline \multirow{3}{*}{ Level } & Mean & Deviation & Range & Lowest score & $\begin{array}{c}\text { Highest } \\
\text { score }\end{array}$ \\
\hline & 21.62 & 9.03 & 31.00 & 8.00 & 39.00 \\
\hline & Standard score & $\mathrm{T}$ score & Distance $(\mathrm{cm})$ & Number & $\%$ \\
\hline Excellent & -1.51 to less than -0.82 & 34.9 to less than 41.8 & 8 to less than 14.2 & 53 & $\% 33.97$ \\
\hline Very good & -0.82 to less than -0.14 & 41.8 to less than 48.6 & 14.2 to less than 20.4 & 5 & $\% 3.21$ \\
\hline Good & -0.14 to less than 0.55 & 48.6 to less than 55.5 & 20.4 to less than 26.6 & 60 & $\% 38.46$ \\
\hline Fair & 0.55 to less than 1.24 & 55.5 to less than 62.4 & 26.6 to less than 32.8 & 9 & $\% 5.77$ \\
\hline Low & 1.24 to less than 1.93 & 62.4 to less than 69.2 & 32.8 to less than 39 & 29 & $\% 18.59$ \\
\hline \multicolumn{4}{|c|}{ Total } & 156 & 100 \\
\hline
\end{tabular}

Table (8) shows the standard levels and the corresponding raw scores of the ability to make the suitable effort in 11-13 year-old junior free style wrestlers. Raw scores corresponding to the excellent level ranged from $8 \mathrm{~cm}$ to less than $14.2 \mathrm{~cm}$. Number of juniors reaching the excellent level was 53 with a percentage of $33.97 \%$ of the total number of the sample. The very good level ranged from $14.2 \mathrm{~cm}$ to less than $20.4 \mathrm{~cm}$. Number of juniors reaching the very good level was 5 with a percentage of $3.21 \%$ of the total number of the sample. The good level ranged from $20.4 \mathrm{~cm}$ to less than $26.6 \mathrm{~cm}$. Number of juniors reaching the good level was 60 with a percentage of $38.46 \%$ of the total number of the sample. The fair level ranged from $26.6 \mathrm{~cm}$ to less than $32.8 \mathrm{~cm}$. Number of juniors reaching the fair level was 9 with a percentage of $5.77 \%$ of the total number of the sample. The low level ranged from $32.8 \mathrm{~cm}$ to less than $39 \mathrm{~cm}$. Number of juniors reaching the low level was 29 with a percentage of $18.59 \%$ of the total number of the sample. This means that based on percentage of the sample in each level, the order of levels was as follows: good - excellent low - fair - very good. This may be due to the fact that the international law of wrestling counts one point against the player who moves out of the area specified for the combat. This is why coaches train players not to go beyond the wrestling mat. It was because of this that more than $72 \%$ of the sample subjects fall only within the good and excellent levels.

Form (3)

levels of the ability of assess the position

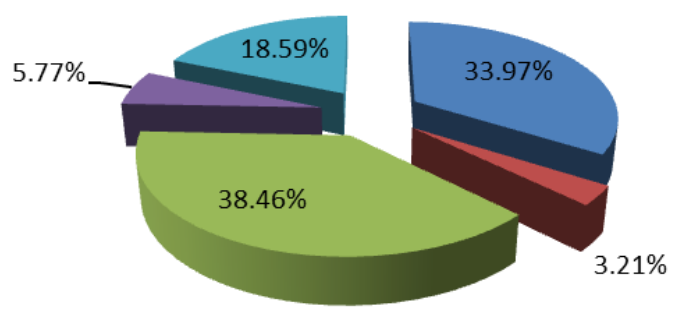

- Excellent
- Very good
- Good
— Fair
- Low

Table (9)

Mean, standard deviation, range and standard levels of the ability of motor Coupling

\begin{tabular}{|c|c|c|c|c|c|}
\hline \multirow{3}{*}{ Level } & Mean & Deviation & Range & Lowest score & $\begin{array}{c}\text { Highest } \\
\text { score }\end{array}$ \\
\cline { 2 - 6 } & 1.66 & 0.40 & 1.92 & 0.59 & 2.51 \\
\cline { 2 - 6 } & Standard score & T score & Time (seconds) & Number & $\%$ \\
\hline Excellent & -2.68 to less than -1.72 & 23.3 to less than 32.9 & 0.59 to less than 0.97 & 6 & $\% 3.85$ \\
\hline Very good & -1.72 to less than -0.76 & 32.9 to less than 42.5 & 0.97 to less than 1.36 & 30 & $\% 19.23$ \\
\hline Good & -0.76 to less than 0.21 & 42.5 to less than 52.1 & 1.36 to less than 1.74 & 55 & $\% 35.26$ \\
\hline Fair & 0.21 to less than 1.17 & 52.1 to less than 61.7 & 1.74 to less than 2.13 & 39 & $\% 25.00$ \\
\hline Low & 1.17 to less than 2.13 & 61.7 to less than 71.3 & 2.13 to less than 2.51 & 26 & $\% 16.67$ \\
\hline \multicolumn{7}{|r|}{ Total } & 156 & 100 \\
\hline
\end{tabular}


Table (9) shows the standard levels and the corresponding raw scores of the ability to make the suitable effort in 11-13 year-old junior free style wrestlers. Raw scores corresponding to the excellent level ranged from $0.59 \mathrm{~s}$ to less than $0.97 \mathrm{~s}$. Number of juniors reaching the excellent level was 6 with a percentage of $3.85 \%$ of the total number of the sample. The very good level ranged from $0.97 \mathrm{~s}$ to less than 1.36s. Number of juniors reaching the very good level was 30 with a percentage of $19.23 \%$ of the total number of the sample. The good level ranged from 1.36s to less than $1.74 \mathrm{~s}$. Number of juniors reaching the good level was 55 with a percentage of $35.26 \%$ of the total number of the sample. The fair level ranged from $1.74 \mathrm{~s}$ to less than $2.13 \mathrm{~s}$. Number of juniors reaching the fair level was 39 with a percentage of $25 \%$ of the total number of the sample. The low level ranged from $2.13 \mathrm{~s}$ to less than 2.51s. Number of juniors reaching the low level was 26 with a percentage of $16.67 \%$ of the total number of the sample. This means that based on percentage of the sample in each level, the order of levels was as follows: good - fair - very good - low excellent. The relatively low percentage in the level of the sample subjects in this coordination ability may be due to the fact that many wrestling coaches neglect training on the combined skills, as indicated by El-Sayed El-Mohamady Kandil (5) though Dick and Frank emphasized that the ability of motor Coupling help stabilize the motor tracks of skills through nervous passages thus leading to smooth and rapid combined skillful performance. (19)

Form (4)

levels of the ability of motor Coupling

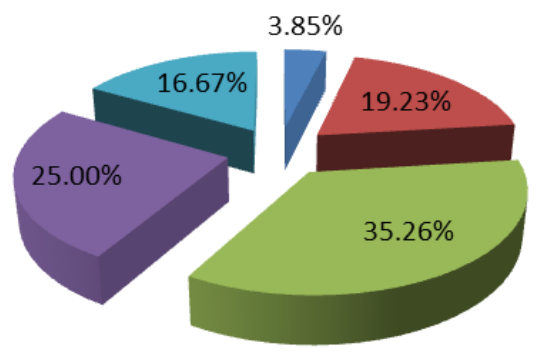

Excellent
Very good
Good
Fair
Low

Table (10)

Mean, standard deviation, range and standard levels of the ability to adapt to changing positions

\begin{tabular}{|c|c|c|c|c|c|}
\hline \multirow{2}{*}{ Level } & Mean & Deviation & Range & Lowest score & $\begin{array}{c}\text { Highest } \\
\text { score }\end{array}$ \\
\cline { 2 - 6 } & 12.07 & 2.00 & 9.31 & 9.01 & 18.32 \\
\cline { 2 - 7 } & Standard score & T score & Time (seconds) & Number & $\%$ \\
\hline Excellent & -1.54 to less than -0.63 & 34.7 to less than 43.7 & 9.01 to less than 10.8 & 26 & $\% 16.67$ \\
\hline Very good & -0.63 to less than 0.27 & 43.7 to less than 52.7 & 10.8 to less than 12.6 & 80 & $\% 51.28$ \\
\hline Good & 0.27 to less than 1.17 & 52.7 to less than 61.7 & 12.6 to less than 14.4 & 31 & $\% 19.87$ \\
\hline Fair & 1.17 to less than 2.07 & 61.7 to less than 70.7 & 14.4 to less than 16.2 & 12 & $\% 7.69$ \\
\hline Low & 2.07 to less than 2.96 & 70.7 to less than 79.7 & 16.2 to less than 18.32 & 7 & $\% 4.49$ \\
\hline & & & & 156 & 100 \\
\hline
\end{tabular}

Table (10) shows the standard levels and the corresponding raw scores of the ability to make the suitable effort in 11-13 year-old junior free style wrestlers. Raw scores corresponding to the excellent level ranged from $9.01 \mathrm{~s}$ to less than 10.8s. Number of juniors reaching the excellent level was 26 with a percentage of $16.67 \%$ of the total number of the sample. The very good level ranged from $10.8 \mathrm{~s}$ to less than $12.6 \mathrm{~s}$. Number of juniors reaching the very good level was 80 with a percentage of $51.28 \%$ of the total number of the sample. The good level ranged from $12.6 \mathrm{~s}$ to less than 14.4s. Number of juniors reaching the good level was 31 with a percentage of $19.87 \%$ of the total number of the sample. The fair level ranged from $14.4 \mathrm{~s}$ to less than 16.2s. Number of juniors reaching the fair level was 12 with a percentage of $7.69 \%$ of the total number of the sample. The low level ranged from $16.2 \mathrm{~s}$ to less than $18.32 \mathrm{~s}$. Number of juniors reaching the low level was 7 with a percentage of $4.49 \%$ of the total number of the sample. This means that based on percentage of the sample in each level, the order of levels was as follows: very good - good excellent - fair - low. The high level of the majority of research sample in this test may be due to the nature of free style wrestling which is practiced in complicated dynamic situations where the wrestler uses different levels of the body in the combat such as the high, coma, the middle and the deep levels when falling on the feet as indicated by 
Mossad Aly Mahmoud (2005) (15). This also conforms with results reached by Gierczuk, D. \& Ljach W. (2012) who stressed that wrestlers had the ability to adapt to changing positions. (21)

Form (5)

levels of the ability of adapt to changing positions

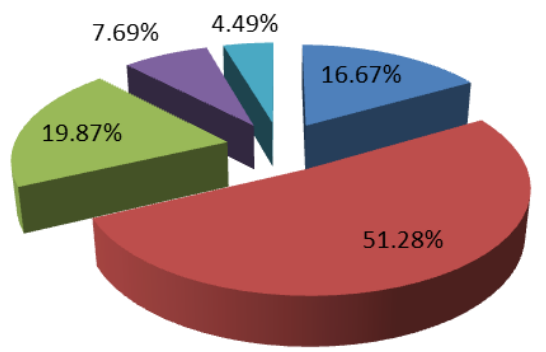

$\%$

Table (11)

Mean, standard deviation, range and standard levels of the ability of motor balance

\begin{tabular}{|c|c|c|c|c|c|}
\hline \multirow{2}{*}{ Level } & Mean & Deviation & Range & Lowest score & $\begin{array}{c}\text { Highest } \\
\text { score }\end{array}$ \\
\cline { 2 - 6 } & 7.94 & 1.72 & 6.38 & 5.33 & 11.71 \\
\cline { 2 - 6 } & Standard score & T score & Time (seconds) & Number & $\%$ \\
\hline Excellent & -1.52 to less than -0.78 & 34.8 to less than 42.2 & 5.33 to less than 6.61 & 44 & $\% 28.21$ \\
\hline Very good & -0.78 to less than -0.04 & 42.2 to less than 49.7 & 6.61 to less than 7.88 & 40 & $\% 25.64$ \\
\hline Good & -0.04 to less than 0.71 & 49.7 to less than 57.1 & 7.88 to less than 9.16 & 16 & $\% 10.26$ \\
\hline Fair & 0.71 to less than 1.45 & 57.1 to less than 64.5 & 9.16 to less than 10.43 & 43 & $\% 27.56$ \\
\hline Low & 1.45 to less than 2.19 & 64.5 to less than 71.9 & 10.43 to less than 11.71 & 13 & $\% 8.33$ \\
\hline & \multicolumn{2}{|c}{ Total } & 156 & 100 \\
\hline
\end{tabular}

Table (11) shows the standard levels and the corresponding raw scores of the ability to make the suitable effort in 11-13 year-old junior free style wrestlers. Raw scores corresponding to the excellent level ranged from $5.33 \mathrm{~s}$ to less than 6.61s. Number of juniors reaching the excellent level was 44 with a percentage of $28.21 \%$ of the total number of the sample. The very good level ranged from $6.61 \mathrm{~s}$ to less than $7.88 \mathrm{~s}$. Number of juniors reaching the very good level was 40 with a percentage of $25.64 \%$ of the total number of the sample. The good level ranged from $7.88 \mathrm{~s}$ to less than 9.16s. Number of juniors reaching the good level was 16 with a percentage of $10.26 \%$ of the total number of the sample. The fair level ranged from $9.16 \mathrm{~s}$ to less than $10.43 \mathrm{~s}$. Number of juniors reaching the fair level was 43 with a percentage of $27.56 \%$ of the total number of the sample. The low level ranged from $10.43 \mathrm{~s}$ to less than 11.71s. Number of juniors reaching the low level was 13 with a percentage of $8.33 \%$ of the total number of the sample. This means that based on percentage of the sample in each level, the order of levels was as follows: excellent fair - very good - good - low. This conforms with the study by Gierczuk, D. (2008) who suggested that free style wrestlers had the ability of motor balance (20). This also conforms with results reached by Mossad Aly Mahmoud (2005) who said that wrestling of both types contribute to developing balance whether static or dynamic which results from the wrestlers' care to keep a suitable supporting base between his feet so as not to lose balance in the face of the pressures practiced by the opponent's force. (15)

Form (6)

levels of the ability of motor balance

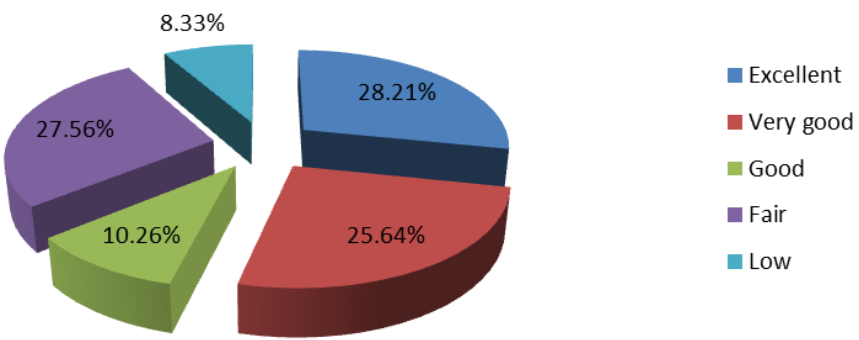


Values of raw scores and the corresponding standard levels in testing each coordination ability show the variety in juniors' levels compared to peers. This helps us reach some positive results which we can use in evaluating performance objectively and guide the training of juniors in this age span. It also conforms with results reached by Muhammad Sobhy Hassanein (2004) (12) who said that raw scores deduced from applying the tests will have no significance unless referred to a standard that will give a meaning to these scores. This will help us identify the situation of each subject compared to the whole group, and whether he is above average, average or below average and how far he is from the average of the whole group and his position compared to peers of the standardization sample subjects. This gives the answer to the research question.

\section{Conclusions:}

Based on result of the research and in the light of research objective and question and procedures in study sample, the following conclusions were reached:

-The Specific coordination of motor abilities of the junior free wrestler are the ability of motor Coupling - the ability to assess position - the ability to make the suitable effort - the ability to adapt to changing positions - the ability of Reaction- the ability of motor balance;

-An objective test battery was designed to measure the coordination of motor abilities studied, and was applied to a sample of 11-13 year-old juniors;

-The standard levels of coordination of motor abilities were identified (the ability of motor Coupling - the ability to assess position - the ability to make the suitable effort - the ability to adapt to changing positions - the ability of Reaction - the ability of motor balance) for 11-13 year-old junior free wrestlers;

-Values of raw scores and the corresponding standard levels in testing each coordination of motor ability show the variety in juniors' levels compared to peers. This helps us reach some positive results which we can use in evaluating performance objectively and guide the training of juniors in this age span.

\section{Recommendations:}

As far as the research sample and conclusions reached are concerned, the author made the following recommendations:

-The coordination of motor ability tests studied (the ability of motor Coupling - the ability to assess position - the ability to make the suitable effort the ability to adapt to changing positions - the ability of Reaction - the ability of motor balance) should be used in evaluating and classifying the level of junior free wrestlers;
-The coordination of motor abilities should be used as a guide in training junior free style and GrecoRoman wrestling juniors and upgrading their skillful levels;

- Conducting further research to identify the special coordination of motor abilities and their development in individual and team sport activities;

- Conducting further research to deduce standard levels for the coordination of motor abilities of juniors in different age stages in the two types of wrestling and also in the rest of individual and team activities;

- Guided training programs should be designed to upgrade the level of coordination of motor abilities and skillful and tactical performance in free style and Greco-Roman wrestling in young age stage.

\section{References}

\section{References in Arabic}

1. Abu El-Ela Abd El-Fatah 1985: Sport Biology, Dar Al-Maarif, $8^{\text {th }}$ edition, Cairo, page 13.

2. Ahmed Khater and Aly El-Beik 1996: Measurement in Sport, Dar Al-Kitab Al-Hadeeth, $4^{\text {th }}$ edition, Cairo, page 30.

3. Ossama Kamel Rateb and Amin Anwar El-Kholy 1994: Motor Education of the Child, $3^{\text {rd }}$ edition, Dar Al-Fikr Al-Arabi, Cairo, pp. 94, 114 and 129.

4. Ossama Kamel Rateb 1999: Motor Growth: An Introduction to Integrated Growth of Child and Adolescent, Dar Al-Fikr Al-Arabi, Cairo, pp. 30, 98-99.

5. El-Sayd El-Mohamady Kandil 2012: The Effect of Special Coordination Ability Exercises on the Combined Skillful Performance Level in Free Style Wrestlers, Journal of Physical Education and Sport Sciences, Faculty of Physical Education, Mansoura University, September, No. 19. Pp. 122 and 128 .

6. El-Sayed Abd El-Maksoud 1986: Theories of Motion, Dar Al-Fikr Al-Arabi, Cairo, p. 261.

7. Khaled Farid Ezzat 2007: The Effect of Specific Exercise Program to Develop the Coordination Abilities on Some Aspects of Attention and the Technical Performance Level of Judo Juniors, An unpublished Ph.D. Dissertation, Faculty of Physical Education, Mansoura University, p. 12.

8. Rabha Muhammad Lotfy 1997: Some Coordination Abilities and their Relationship to the Level of Performing the Peaceful Shot of Basketball Female Beginners, Journal of Physical 
Education and Sport, No. 27, Faculty of Physical Education for Boys, Helwan University, p. 71.

9. Amr Muhammad Mostafa 1998: A Factorial Study of Coordination Abilities of Wrestlers in Egypt, a Ph.D. dissertation, Faculty of Physical Education for Boys, Helwan University, p. 25.

10. Kamal Abd El-Hameed and Muhammad Nasr ElDin 1994: Introduction to Evaluation in Physical Education, Dar Al-Fikr Al-Arabi, $1^{\text {st }}$ edition, Cairo, pp. 183-184, 187.

11. Muhammad Allawy and Muhammad Nasr El-Din 2000: Measurement in Physical Education and Sport Psychology, $1^{\text {st }}$ edition, Dar Al-Fikr AlArabi, Cairo, pp. 302, 303.

12. Muhammad Sobhy Hassanein 2004: Measurement and Evaluation in Physical Education and Sport, Part $1,6^{\text {th }}$ edition, Dar Al-Fikr Al-Arabi, Cairo, pp. 29-30, 28.

13. Muhammad Abd El-Sattar 2012: Identifying Standard Levels of Some Coordination Abilities of Soccer Juniors, an unpublished Ph.D. Dissertation, Faculty of Physical Education, Mansoura University, p. 1.

14. Muhammad Lotfy El-Sayed 2006: Sport Achievement and Training Work Rules, $1^{\text {st }}$ edition, Markaz Al-Kitab Lel-Nashr, p. 53.

15. Mossad Aly Mahmoud 2005: Encyclopedia of Free Wrestling for Amateurs, Faculty of Physical Education, Mansoura University, pp. 47, 108

16. Juhans Rea Engborg Rieter 1988: Introduction to Theories and General Training Methods "Motor Coordination and Sport Technique", the Public German Institution of Physical Education, translated by Jurgen Schleif, Leipzig, Democratic Republic of Germany, p. 11.

\section{References in Foreign Languages:}

17. August Neumaier 2009: Koordinative Anforderungs profil und Koordinations training, Sportverlag Strauß, , 4. überarbeitete Auflage, Köln,p9

18. Bob Davis, Ros Bull 1995: Physical Education and the Study of Sport, Second Edition, Mosby Publisher, London,p116.

19. Dick, Frank. W, (1992) : Sports Training Principals. 2th ed, A \& C Black Publishers, LTD, London,p153

20. Gierczuk. D. (2008). Level of selected indicators of coordination motor abilities in Greco-Roman and freestyle wrestlers aged 1314. Polish Journal of Sport and Tourism 15(4), 192 199.p194
21. Gierczuk, D. \& Ljach w. (2012). Evaluating the coordination of motor abilities in Greco-Roman wrestlers by computer testing. Human Movement 13(4), 323 -329. P329

22. Julius Kasa: Relationship of motor abilities and motor skills in sport games, www.awf.krakow.pl/jedn/gryzesps.pdf p129 
